\title{
Correction: Rogowska et al. Changes in Stress, Coping Styles, and Life Satisfaction between the First and Second Waves of the COVID-19 Pandemic: A Longitudinal Cross-Lagged Study in a Sample of University Students. J. Clin. Med. 2021, 10, 4025
}

\author{
Aleksandra Maria Rogowska ${ }^{1, * \mathbb{D}}$, Cezary Kuśnierz $^{2} \mathbb{D}$ and Dominika Ochnik ${ }^{3}$ (D) \\ Institute of Psychology, Faculty of Social Sciences, University of Opole, 45-052 Opole, Poland \\ 2 Faculty of Physical Education and Physiotherapy, Opole University of Technology, 45-758 Opole, Poland; \\ c.kusnierz@po.edu.pl \\ 3 Faculty of Medicine, University of Technology, 40-555 Katowice, Poland; dominika.ochnik@wst.pl \\ * Correspondence: arogowska@uni.opole.pl
}

Citation: Rogowska, A.M.; Kuśnierz, C.; Ochnik, D. Correction: Rogowska et al. Changes in Stress, Coping Styles, and Life Satisfaction between the First and Second Waves of the COVID-19 Pandemic: A Longitudinal Cross-Lagged Study in a Sample of University Students. J. Clin. Med. 2021, 10, 4025. J. Clin. Med. 2022, 11, 276. https://doi.org/10.3390/jcm 11010276

Received: 5 November 2021 Accepted: 19 November 2021 Published: 5 January 2022

Publisher's Note: MDPI stays neutral with regard to jurisdictional claims in published maps and institutional affiliations.

Copyright: (C) 2022 by the authors. Licensee MDPI, Basel, Switzerland. This article is an open access article distributed under the terms and conditions of the Creative Commons Attribution (CC BY) license (https:// creativecommons.org/licenses/by/ $4.0 /)$
The authors wish to make the following corrections to this paper [1]:

\section{Change in Abstract}

The sentence "The task-oriented and avoidance-oriented coping styles can play a mediating role in the reciprocal relationship between life satisfaction and perceived stress during W1 and W2 of the pandemic" is changed into "The task-oriented and emotionoriented coping styles can play a mediating role in the reciprocal relationship between life satisfaction and perceived stress during W1 and W2 of the pandemic".

\section{Change in Main Body Paragraph}

In the Discussion section (8th paragraph), the following sentence "Avoidance-oriented coping was not found to be a significant predictor of stress. Therefore, this coping style plays a mediating role in the relationship between life satisfaction and stress." is modified into "Avoidance-oriented coping was not found to be a significant predictor of stress. Therefore, this coping style cannot play a mediating role in the relationship between life satisfaction and stress".

The authors apologize for any inconvenience caused and state that the scientific conclusions are unaffected. The original article has been updated.

\section{Reference}

1. Rogowska, A.M.; Kuśnierz, C.; Ochnik, D. Changes in Stress, Coping Styles, and Life Satisfaction between the First and Second Waves of the COVID-19 Pandemic: A Longitudinal Cross-Lagged Study in a Sample of University Students. J. Clin. Med. 2021, 10, 4025. [CrossRef] [PubMed] 